\title{
Microbial Production of Chiral Hydroxy Esters and Their Analogs: Biocatalytic Reduction of Carbonyl Compounds by Actinobacteria, Agromyces and Gordonia Strains
}

\author{
Kohji Ishihara1 ${ }^{*}$, Natsumi Adachi', Takumu Mishima1, Chiharu Kuboki', Ayaka Shuto', \\ Kazuya Okamoto1, Manami Inoue', Hiroki Hamada1, Daisuke Uesugi², Noriyoshi Masuoka ${ }^{3}$, \\ Nobuyoshi Nakajima ${ }^{4}$
}

${ }^{1}$ Department of Life Science, Okayama University of Science, Okayama, Japan ${ }^{2}$ Department of Research \& Development, JO Cosmetics Co., Ltd., Tokyo, Japan ${ }^{3}$ Department of Research \& Development, Institute for Fruit Juice Research in Tsudaka, Co., Ltd., Okayama, Japan ${ }^{4}$ Department of Nutritional Science, Okayama Prefectural University, Soja, Okayama, Japan

Email: *ishihara@dls.ous.ac.jp

How to cite this paper: Ishihara, K., Adach, N., Mishima, T., Kuboki, C., Shuto, A., Okamoto, K., Inoue, M., Hamada, H., Uesugi, D., Masuoka, N. and Nakajima, N. (2019) Microbial Production of Chiral Hydroxy Esters and Their Analogs: Biocatalytic Reduction of Carbonyl Compounds by Actinobacteria, Agromyces and Gordonia Strains. Advances in Enzyme Research, 7, 15-25.

https://doi.org/10.4236/aer.2019.72002

Received: June 8, 2019

Accepted: June 27, 2019

Published: June 30, 2019

Copyright (c) 2019 by author(s) and Scientific Research Publishing Inc. This work is licensed under the Creative Commons Attribution International License (CC BY 4.0).

http://creativecommons.org/licenses/by/4.0/

\begin{abstract}
We screened 15 Agromyces strains from the Microbacteriaceae family and 16 Gordonia strains from the Gordoniaceae family to investigate their biocatalytic ability to reduce carbonyl compounds. Two Agromyces strains (A. soli NBRC109063 and A. humatus NBRC109085) and two Gordonia strains ( $G$. hydrophobica NBRC16057 and G. malaquae NBRC108250) grew well in 230 medium. The stereoselective reduction of various carbonyl compounds using these four strains was investigated. We discovered that these strains can reduce aliphatic and aromatic $\alpha$-keto esters and an aromatic $\alpha$-keto amide. On the basis of the conversion rate and stereoselectivity of the alcohols produced, G. hydrophobica NBRC16057 is a potential biocatalyst for the stereoselective reduction of $\alpha$-keto esters and an aromatic $\alpha$-keto amide to the corresponding chiral alcohols. Our results also suggest that the reduction of ethyl 2-methylacetoacetate by wet $G$. hydrophobica NBRC16057 cells in the presence of L-glutamate is useful for the production of chiral ethyl 3-hydroxy-2-methylbutanoate.
\end{abstract}

\section{Keywords}

Actinobacteria, Stereoselective Reduction, Carbonyl Reductase, Chiral Alcohol 


\section{Introduction}

Biotransformation has been extensively investigated because it is useful for converting inexpensive and plentiful organic compounds into costly and valuable ones [1] [2] [3]. In particular, microbial reduction of carbonyl compounds is a convenient and environmentally-friendly method for obtaining optically pure alcohols. For example, bakers' yeast and fungi have often been used for the reduction of carbonyl compounds to obtain optically active hydroxy esters [4] [5] [6] [7]. To date, several studies concerning the reduction of keto esters and their analogs with other microorganisms such as actinomycetes have been reported. In particular, Streptomycetaceae (Streptomyces, Kitasatospora, and Streptacidiphilus genera) [8] [9] [10] [11] [12], Streptosporangiaceae (Nonomuraea and Streptosporangium genera) [13], and Micromonosporaceae (Salinispora, Actinoplanes, and Dactylosporangium genera) [14] [15] families have been studied for the biocatalytic activities of their members. Furthermore, several keto ester reductases have been purified from $S$. thermocyaneoviolaceus, $S$. coelicolor A3(2), and $S$. avermitilis whole cells, and the reaction mechanism of the reduction reaction has been elucidated based on the enzymatic properties of these reductases [16] [17] [18]. However, the potential biocatalytic abilities of actinomycetes belonging to other families have not been investigated.

In this study, we investigated the stereoselective reduction of carbonyl compounds using two genera, Agromyces from the Microbacteriaceae family and Gordonia from the Gordoniaceae family, as novel biocatalysts (Figure 1).

\section{Materials and Methods}

\subsection{Instruments and Chemicals}

Gas chromatography (GC) was performed using a GL Science GC-353 gas chromatograph (GL Science Inc., Japan) equipped with capillary columns (DB-WAX, $0.25 \mu \mathrm{m}, 0.25 \mathrm{~mm} \times 30 \mathrm{~m}$, Agilent Technologies, USA; TC-1, 0.25 $\mu \mathrm{m}, 0.25 \mathrm{~mm} \times 30 \mathrm{~m}$, GL Science Inc.; CP-Chirasil-DEX CB, $0.25 \mu \mathrm{m}, 0.25 \mathrm{~mm} \times$

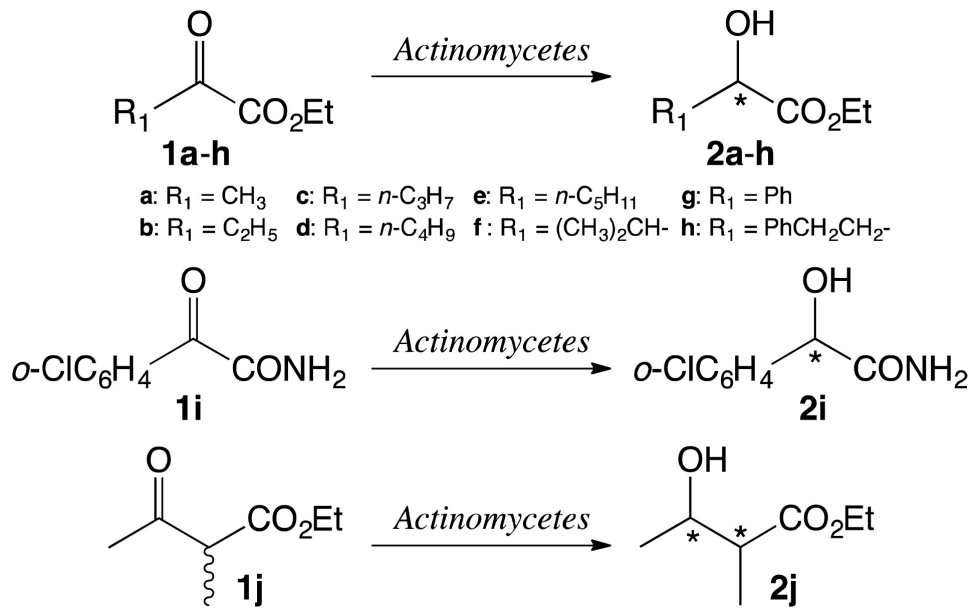

Figure 1. The reduction of carbonyl compounds by actinomycetes. 
$25 \mathrm{~m}$, Varian Inc., USA; Gamma DEX 225, $0.25 \mu \mathrm{m}, 0.25 \mathrm{~mm} \times 30 \mathrm{~m}$, Sigma-Aldrich Inc., USA). Ethyl pyruvate (Figure 1, 1a), diatomaceous earth (granular), sodium hydrogen L-glutamate monohydrate, magnesium sulfate heptahydrate, glycerol, and hipolypepton were purchased from Wako Pure Chemical Industries Ltd. (Japan). Bacto ${ }^{\mathrm{Tm}}$ malt extract, Bacto ${ }^{\mathrm{TM}}$ yeast extract, Bacto ${ }^{\mathrm{TM}}$ brain heart infusion, and Bacto ${ }^{\mathrm{Tm}}$ tryptic soy broth were purchased from Becton Dickinson and Co. (USA). Ethyl lactate (2a), ethyl 3-methyl-2-oxobutanoate (1f), ethyl 2-oxo-4-phenylbutanoate (1h), ethyl 2-hydroxy-4-phenylbutanoate $(2 \mathrm{~h})$, and beef extract were purchased from Sigma-Aldrich Inc. Ethyl benzoylformate $(\mathbf{1 g})$, ethyl 2-methylacetoacetate $(\mathbf{1 j})$, and ethyl mandelate $(\mathbf{2 g})$ were obtained from Tokyo Chemical Industry, Co., Ltd. (Japan). Ethyl 2-oxobutanoate (1b), ethyl 2-oxopentanoate (1c), ethyl 2-oxohexanoate (1d), ethyl 2-oxoheptanoate (1e), 2-chlorobenzoylformamide (1i), 2-chloromandelamide (2i), $\alpha$-hydroxy esters $(\mathbf{2} \mathbf{b}-\mathbf{f})$, and ethyl 3 -hydroxy-2-methylbutanoate $(\mathbf{2} \mathbf{j})$ were prepared as described previously [4] [7] [19]. All other chemicals used in this study were of analytical grade and commercially available.

\subsection{Microorganisms and Culture}

Agromyces ramosus NBRC13899, Agromyces cerinus subsp. cerinus NBRC15780, Agromyces luteolus NBRC16235, Agromyces rhizospherae NBRC16236, Agromyces brachium NBRC16238, Agromyces albus NBRC103057, Agromyces iriomotensis NBRC106452, Agromyces subtropicus NBRC106454, Agromyces marinus NBRC109019, Agromyces soli NBRC109063, Agromyces flavus NBRC109064, Agromyces tropicus NBRC109073, Agromyces ulmi NBRC109083, Agromyces neolithicus NBRC109084, Agromyces humatus NBRC109085, Gordonia amarae NBRC15530, Gordonia hydrophobica NBRC16057, Gordonia rhizosphera NBRC16068, Gordonia polysprenivorans NBRC16320, Gordonia alkanivorans NBRC16433, Gordonia terrae NBRC100016, Gordonia namibiensis NBRC108229, Gordonia sihwensis NBRC108236, Gordonia westaflica NBRC108237, Gordonia paraffinivorans NBRC108238, Gordonia soli NBRC108243, Gordonia malaquae NBRC108250, Gordonia alkaliphila NBRC109776, Gordonia jinhuaensis NBRC110001, Gordonia defluvi NBRC110695, and Gordonia sinesedis NBRC110696 were purchased from the National Institute of Technology and Evaluation, Biological Resource Center (NBRC; Japan). These strains were maintained at $25^{\circ} \mathrm{C}$ in NBRC-recommended media $(227,230,253$, and 802$)$ solidified with $1.5 \%(\mathrm{w} / \mathrm{v})$ agar. The 227 medium contained $4.0 \mathrm{~g}$ of Bacto $^{\text {th }}$ yeast extract, $10.0 \mathrm{~g}$ of Bacto ${ }^{\mathrm{mi}}$ malt extract, and $4.0 \mathrm{~g}$ of D-glucose per liter of distilled water ( $\mathrm{pH} 7.3$ ). The 230 medium contained $30.0 \mathrm{~g}$ of Bacto ${ }^{\mathrm{Tw}}$ tryptic soy broth per liter of distilled water ( $\mathrm{pH}$ 7.3). The 253 medium contained $37.0 \mathrm{~g}$ of Bacto $^{\text {ta }}$ brain heart infusion per liter of distilled water ( $\mathrm{pH}$ 7.3). The 802 medium contained $2.0 \mathrm{~g}$ of hipolypepton, $2.0 \mathrm{~g}$ of Bacto $^{\text {Tm }}$ yeast extract, and $1.0 \mathrm{~g}$ of magnesium sulfate heptahydrate per liter of distilled water ( $\mathrm{pH} 7.0)$. The 15 Agromyces strains were grown in $227,230,253$, and 802 media for 8 days at $25^{\circ} \mathrm{C}$ with aerobic shaking in 
baffled flasks in the dark, and the 16 Gordonia strains were grown in 227, 230, 231, and 802 media for 8 days at $25^{\circ} \mathrm{C}$ with aerobic shaking in baffled flasks in the dark. The actinomycetes were harvested by filtration on filter paper (Whatman No. 4) or glass fiber filters (ADVANTEC GA-55) in vacuo and washed with saline $(0.85 \% \mathrm{NaCl}$ aq.). The harvested cells were immediately used for reduction after washing with the saline.

\subsection{Reduction of $\alpha$ - and $\beta$-Keto Esters, and an Aromatic $\alpha$-Keto Amide Using Actinomycete Cells}

Wet saline-washed wet actinomycete cells $(0.5 \mathrm{~g}$, dry weight approximately 0.15 g) were resuspended in a test tube $(\phi 30 \mathrm{~mm} \times 200 \mathrm{~mm})$ containing $20 \mathrm{~mL}$ of saline. The substrate $(0.15 \mathrm{mmol} ; 7.5 \mathrm{mM})$ and additive $(5.0 \mathrm{mmol} ; 250 \mathrm{mM})$ were then added, and the reaction mixture was incubated aerobically (with reciprocated shaking at $120 \mathrm{rpm})$ at $25^{\circ} \mathrm{C}$. A portion $(0.5 \mathrm{~mL})$ of the mixture was applied to a short diatomaceous earth column $(\phi 10 \mathrm{~mm} \times 30 \mathrm{~mm})$, extracted with diethyl ether $(5.0 \mathrm{~mL})$, and then concentrated under reduced pressure.

\subsection{Analysis}

The production of alcohols (Figure 1, 2a-j) was measured using GC with a DB-WAX capillary column ( $100 \mathrm{kPa}$ He at $110^{\circ} \mathrm{C}$ : $1 \mathrm{a}, 3.78 \mathrm{~min} ; 2 \mathrm{a}, 4.75 \mathrm{~min} ; \mathbf{1 b}$, $4.73 \mathrm{~min} ; 2 \mathrm{~b}, 5.92 \mathrm{~min} ; 1 \mathrm{f}, 4.54 \mathrm{~min} ; 2 \mathrm{f}, 6.41 \mathrm{~min} ; 120^{\circ} \mathrm{C}: 1 \mathrm{c}, 4.84 \mathrm{~min} ; 2 \mathrm{c}, 6.45$ min; $1 \mathbf{j}$, $5.54 \mathrm{~min} ; 2 \mathrm{j}$-anti from, $7.62 \mathrm{~min} ; 2 \mathrm{j}$-syn form, $8.13 \mathrm{~min} ; 150^{\circ} \mathrm{C}: 1 \mathrm{~d}, 3.83$ min; $2 \mathrm{~d}, 4.68 \mathrm{~min} ; 1 \mathrm{e}, 4.78 \mathrm{~min} ; 2 \mathrm{e}, 6.07 \mathrm{~min} ; 180^{\circ} \mathrm{C}: 1 \mathrm{~g}, 9.01 \mathrm{~min} ; 2 \mathrm{~g}, 12.08$ min) or a TC- 1 capillary column $\left(100 \mathrm{kPa} \mathrm{He}\right.$ at $140^{\circ} \mathrm{C}: 1 \mathrm{~h}, 10.02 \mathrm{~min} ; 2 \mathrm{~h}, 10.96$ $\min ; 170^{\circ} \mathrm{C}$ : $1 \mathbf{i}, 6.85 \mathrm{~min} ; 2 \mathbf{i}, 8.34 \mathrm{~min}$ ). The enantiomeric excess (e.e.) of the product was measured using a GC instrument equipped with an optically active CP-Chirasil-DEX CB (2a-e, 2g-h, and $\mathbf{2 j}$ ) or a Gamma DEX 225 capillary column $(\mathbf{2} \mathbf{f}$ and $\mathbf{2} \mathbf{i})$. The e.e. was calculated using the following formula: e.e. $(\%)=$ $\{(R-S) /(R+S)\} \times 100$, where $R$ and $S$ are the respective peak areas of the isomer in GC analyses. The absolute configurations of the $\alpha$ - and $\beta$-hydroxy esters ( $2 \mathrm{a}-\mathrm{h}$ and $2 \mathbf{j}$ ), and the $\alpha$-hydroxy amide ( $2 \mathbf{i})$ were identified by comparing their retention times as determined by the GC analyses with those of authentic samples [4] [7] [19].

\section{Results and Discussion}

\subsection{Screening of Actinomycete Strains and Culture Media}

To determine the most suitable medium for liquid culture, 15 Agromyces and 16 Gordonia strains were cultivated in several culture media, after which the wet weight of the cells was measured. All Agromyces strains grew poorly in 227, 253, and 802 media, even after 8 days of culture, and the resulting wet cell weights were $0.2 \mathrm{~g}$ or less (see Table 1). However, two strains, $A$. soli NBRC109063 and A. humatus NBRC109085, yielded more than $0.4 \mathrm{~g}$ of wet cells $/ 100 \mathrm{~mL}$ of culture in the 230 medium, even though the recommended medium for NBRC109063 
Table 1. The cultivation of Agromyces strains in several culture media.

\begin{tabular}{cccccc}
\hline \multirow{2}{*}{$\begin{array}{c}\text { NBRC } \\
\text { No. }\end{array}$} & Scientific Name & $\mathbf{5}$ Wet cells weight (g) \\
\cline { 3 - 6 } & & $\mathbf{2 2 7}$ & $\mathbf{2 3 0}$ & $\mathbf{2 5 3}$ & $\mathbf{8 0 2}$ \\
\hline 13899 & Agromyces ramosus & $<0.1$ & $<0.1$ & $<0.1$ & $<0.1$ \\
15780 & Agromyces cerinus & $<0.1$ & $<0.1$ & $<0.1$ & $<0.1$ \\
16235 & Agromyces luteolus & $<0.1$ & $<0.1$ & 0.2 & 0.2 \\
16236 & Agromyces rhizosperae & $<0.1$ & $<0.1$ & $<0.1$ & 0.2 \\
16238 & Agromyces bracchium & $<0.1$ & $<0.1$ & $<0.1$ & $<0.1$ \\
103057 & Agromyces albus & 0.2 & 0.1 & 0.2 & 0.2 \\
106452 & Agromyces iriomotensis & $<0.1$ & $<0.1$ & $<0.1$ & $<0.1$ \\
106454 & Agromyces subtropicus & 0.2 & 0.1 & 0.1 & 0.2 \\
109019 & Agromyces marinus & 0.2 & $<0.1$ & 0.2 & 0.2 \\
109063 & Agromyces soli & 0.2 & 0.4 & 0.2 & 0.2 \\
109064 & Agromyces flavus & 0.2 & $<0.1$ & 0.2 & 0.2 \\
109073 & Agromyces tropicus & 0.2 & 0.3 & 0.2 & 0.2 \\
109083 & Agromyces ulmi & 0.1 & $<0.1$ & 0.1 & 0.1 \\
109084 & Agromyces neolithicus & 0.2 & 0.2 & 0.2 & 0.2 \\
109085 & Agromyces humatus & 0.2 & 0.6 & 0.2 & 0.2 \\
\hline
\end{tabular}

The actinomycetes were grown in liquid medium $(100 \mathrm{~mL})$ at $25^{\circ} \mathrm{C}$ for 8 days with aerobic reciprocating shaking $(100 / \mathrm{min})$ in baffled $500-\mathrm{mL}$ flask in the dark.

and NBRC109085 strain is 802 medium. These results suggest that the peptone contained in the culture medium is more likely to be assimilated from plants than from animals in liquid cultures of Agromyces strains. As in the case of the genus Agromyces, Gordonia strains also had poor growth in various liquid media. Only two strains, G. hydrophobica NBRC16057 and G. malaquae NBRC108250, yielded more than $0.4 \mathrm{~g}$ of wet cells $/ 100 \mathrm{~mL}$ of the liquid culture in the 230 medium (see Table 2).

Therefore, we investigated the potential ability of two Agromyces strains (NBRC109063 and NBRC109085) and two Gordonia strains (NBRC16057 and NBRC108250) to act as biocatalysts for the asymmetric reduction of carbonyl compounds.

\subsection{Reduction of Carbonyl Compounds by Agromyces Wet Cells}

Two actinomycete strains (A. soli NBRC109063 and A. humatus NBRC109085) cultivated in the 230 medium were tested for their ability to reduce several carbonyl compounds (1a-j) (Figure 1). The results of the microbial reductions are summarized in Table 3 and Table 4. Both strains could reduce aliphatic and aromatic $\alpha$-keto esters $(1 \mathbf{a}-\mathbf{h})$ and an aromatic $\alpha$-keto amide (1i). Among the reduction of nine substrates tested, there were compounds in which the conversion rate was over $99 \%(2 \mathrm{c}, 2 \mathrm{~d}$, and $2 \mathrm{f})$; however, the reduction of most substrates showed only low values to moderate conversion rates. Moreover, the 
Table 2. The cultivation of Gordonia strains in several culture media.

\begin{tabular}{ccccc}
\hline \multirow{2}{*}{$\begin{array}{c}\text { NBRC } \\
\text { No. }\end{array}$} & Scientific Name & \multicolumn{3}{c}{ Wet cells weight (g) } \\
\cline { 3 - 5 } & & 227 & 230 & 802 \\
15530 & Gordonia amarae & 0.1 & $<0.1$ & $<0.1$ \\
16057 & Gordonia hydrophobica & 0.1 & 0.6 & 0.2 \\
16068 & Gordonia rhizosphera & $<0.1$ & $<0.1$ & $<0.1$ \\
16320 & Gordonia polysoprenivorans & $<0.1$ & $<0.1$ & 0.2 \\
16433 & Gordonia alkanivorans & 0.2 & $<0.1$ & 0.2 \\
100016 & Gordonia terrae & 0.2 & 0.3 & 0.1 \\
108229 & Gordonia namibiensis & 0.2 & $<0.1$ & 0.2 \\
108236 & Gordonia sihwensis & 0.2 & 0.2 & 0.2 \\
108237 & Gordonia westaflica & $<0.1$ & $<0.1$ & $<0.1$ \\
108238 & Gordonia paraffinivorans & 0.2 & $<0.1$ & 0.2 \\
108243 & Gordonia soli & 0.1 & $<0.1$ & 0.2 \\
108250 & Gordonia malaquae & $<0.1$ & 0.4 & $<0.1$ \\
109776 & Gordonia alkaliphila & $<0.1$ & $<0.1$ & $<0.1$ \\
110001 & Gordonia jinhuaensis & 0.1 & 0.1 & $<0.1$ \\
110695 & Gordonia defluvi & $<0.1$ & $<0.1$ & $<0.1$ \\
110696 & Gordonia sinesedis & 0.1 & 0.3 & $<0.1$ \\
\hline
\end{tabular}

The actinomycetes were grown in liquid medium $(100 \mathrm{~mL})$ at $25^{\circ} \mathrm{C}$ for 8 days with aerobic reciprocating shaking $(100 / \mathrm{min})$ in baffled $500-\mathrm{mL}$ flask in the dark.

Table 3. The reduction of $\alpha$-keto esters and aromatic $\alpha$-keto amide by Agromyces soli NBRC109063.

\begin{tabular}{|c|c|c|c|c|c|c|c|c|c|}
\hline \multirow{3}{*}{ Product } & \multicolumn{3}{|c|}{ No Additive } & \multicolumn{3}{|c|}{ Glycerol } & \multicolumn{3}{|c|}{ L-Glutamate } \\
\hline & \multirow{2}{*}{$\begin{array}{c}\text { Conv. } \\
(\%)\end{array}$} & \multirow{2}{*}{$\begin{array}{l}\text { e.e. } \\
\text { (\%) }\end{array}$} & \multirow{2}{*}{$R / S$} & \multirow{2}{*}{$\begin{array}{c}\text { Conv. } \\
(\%)\end{array}$} & \multirow{2}{*}{$\begin{array}{l}\text { e.e. } \\
(\%)\end{array}$} & \multirow{2}{*}{$R / S$} & \multirow{2}{*}{$\begin{array}{c}\text { Conv. } \\
(\%)\end{array}$} & \multirow{2}{*}{$\begin{array}{l}\text { e.e. } \\
(\%)\end{array}$} & \multirow{2}{*}{$R / S$} \\
\hline & & & & & & & & & \\
\hline $2 a$ & 20 & $>99$ & $S$ & 24 & 81 & $S$ & 89 & 46 & $S$ \\
\hline $2 b$ & 50 & 91 & $R$ & 38 & 22 & $S$ & 80 & 94 & $R$ \\
\hline $2 c$ & $>99$ & 74 & $R$ & 71 & 15 & $S$ & 93 & 86 & $R$ \\
\hline $2 \mathrm{~d}$ & 62 & 86 & $S$ & 60 & 48 & $S$ & $>99$ & $>99$ & $S$ \\
\hline $2 e$ & 82 & 62 & $R$ & 52 & 25 & $S$ & 92 & 87 & $R$ \\
\hline $2 f$ & 72 & 25 & $S$ & 43 & 78 & $R$ & 80 & 55 & $S$ \\
\hline $2 \mathrm{~g}$ & 52 & 31 & $R$ & 50 & 71 & $S$ & 71 & 45 & $R$ \\
\hline $2 \mathrm{~h}$ & 96 & 95 & $R$ & 69 & 90 & $R$ & 92 & 96 & $R$ \\
\hline $2 \mathrm{i}$ & 3 & 30 & $R$ & 5 & 33 & $R$ & 9 & 41 & $R$ \\
\hline
\end{tabular}

stereoselectivity of the product in the reduction of each substrate also showed low values except for the reduction of ethyl pyruvate (1a). We tried to improve the conversion rate and the stereoselectivity of the alcohols produced by two Agromyces strains by introducing additives (glycerol and sodium hydrogen 
Table 4. The reduction of $\alpha$-keto esters and aromatic $\alpha$-keto amide by Agromyces humatus NBRC109085.

\begin{tabular}{|c|c|c|c|c|c|c|c|c|c|}
\hline \multirow{3}{*}{ Product } & \multicolumn{3}{|c|}{ No Additive } & \multicolumn{3}{|c|}{ Glycerol } & \multicolumn{3}{|c|}{ L-Glutamate } \\
\hline & \multirow{2}{*}{$\begin{array}{c}\text { Conv. } \\
(\%)\end{array}$} & \multirow{2}{*}{$\begin{array}{l}\text { e.e. } \\
\text { (\%) }\end{array}$} & \multirow{2}{*}{$R / S$} & \multirow{2}{*}{$\begin{array}{c}\text { Conv. } \\
(\%)\end{array}$} & \multirow{2}{*}{$\begin{array}{l}\text { e.e. } \\
(\%)\end{array}$} & \multirow{2}{*}{$R / S$} & \multirow{2}{*}{$\begin{array}{c}\text { Conv. } \\
(\%)\end{array}$} & \multirow{2}{*}{$\begin{array}{l}\text { e.e. } \\
(\%)\end{array}$} & \multirow{2}{*}{$R / S$} \\
\hline & & & & & & & & & \\
\hline $2 a$ & 44 & $>99$ & $S$ & 71 & $>99$ & $S$ & 53 & $>99$ & $S$ \\
\hline $2 \mathrm{~b}$ & 78 & 14 & $S$ & 58 & 34 & $S$ & 47 & 21 & $R$ \\
\hline $2 c$ & $>99$ & 44 & $S$ & 98 & 15 & $S$ & 95 & 30 & $R$ \\
\hline $2 d$ & $>99$ & 10 & $S$ & $>99$ & 38 & $S$ & $>99$ & $>99$ & $S$ \\
\hline $2 e$ & 47 & 5 & $S$ & 68 & 17 & $S$ & 35 & 31 & $R$ \\
\hline $2 f$ & $>99$ & 62 & $R$ & $>99$ & 77 & $R$ & $>99$ & 60 & $R$ \\
\hline $2 \mathrm{~g}$ & 71 & 68 & $S$ & 66 & 46 & $S$ & 75 & 65 & $S$ \\
\hline $2 \mathrm{~h}$ & 18 & 6 & $R$ & 23 & 55 & $R$ & 15 & 72 & $R$ \\
\hline $2 \mathrm{i}$ & 49 & 91 & $R$ & 61 & 89 & $R$ & 3 & 21 & $R$ \\
\hline
\end{tabular}

L-glutamate). The introduction of glycerol contributed little to the improvement of conversion rates and stereoselectivity of produced alcohols. The addition of L-glutamate also showed no significant improvement in the reduction of substrates; the reduction of only one substrate (from $1 \mathrm{~d}$ to $\mathbf{2 d}$ ) improved the conversion rate of both NBRC109063 and NBRC109065 wet cells to $>99 \%$ and the stereoselectivity to $>99 \%$ e.e. (S). As shown in Table 5 , reduction of ethyl 2 -methylacetoacetate $(1 \mathbf{j})$, one of $\beta$-keto esters, by the wet cells of NBRC109063 strain showed high values of syn/anti ratios and enantioselectivity. However, the conversion rate from $1 \mathbf{j}$ to $2 \mathbf{j}$ was low and was not improved by the additives. Furthermore, reduction of $1 j$ by the wet NBRC109065 cells resulted in a low syn/anti ratio and low conversion rate and did not improve with the addition of additives.

\subsection{Reduction of Carbonyl Compounds by Gordonia Wet Cells}

Two Gordonia strains (G. hydrophobica NBRC16057 and G. malaquae NBRC108250) cultivated in 230 medium were tested for their ability to reduce the keto esters and keto amide (Table 6 and Table 7). The Gordonia strains could reduce aliphatic and aromatic $\alpha$-keto esters and an aromatic $\alpha$-keto amide. However, as with the reduction by two Agromyces strains, the substrate was reduced only at low to moderate conversion rates, and the stereoselectivity of the products was low except for the reduction of $1 \mathrm{~h}$ by the G. hydrophobica NBRC16057 strain. Therefore, the effects of additives on these microbial reduction reactions were also examined. In the reductions by two Gordonia strains, NBRC16057 and NBRC108250, the introduction of glycerol did not improve the conversion rate or stereoselectivity. On the other hand, the addition of L-glutamate improved the conversion rate and the stereoselectivity of the product. In particular, the reductions of 1a, 1c, 1d, and $\mathbf{1 g}$ by the NBRC16057 wet cells improved the conversion rates to $>99 \%$, and $1 \mathrm{~d}$ and $1 \mathrm{e}$ were reduced to the 
Table 5. The reduction of ethyl 2-methylacetoacetate by two Agromyces strains.

\begin{tabular}{|c|c|c|c|c|c|}
\hline \multirow{2}{*}{ Strain/ NBRC No. } & \multirow{2}{*}{ Additive } & \multirow{2}{*}{$\begin{array}{c}\text { Conv. } \\
(\%)\end{array}$} & \multirow{2}{*}{ Syn/Anti } & \multicolumn{2}{|c|}{ e.e. (\%) } \\
\hline & & & & Syn- $(2 R, 3 S)$ & Anti- $(2 S, 3 S)$ \\
\hline \multirow{3}{*}{$\begin{array}{c}\text { A. soli } \\
\text { NBRC109063 }\end{array}$} & None & 12 & $7 / 93$ & $>99$ & $>99$ \\
\hline & Glycerol & 10 & $11 / 89$ & 86 & $>99$ \\
\hline & L-Glutamate & 23 & $19 / 81$ & $>99$ & $>99$ \\
\hline \multirow{3}{*}{$\begin{array}{c}\text { A. humatus } \\
\text { NBRC109065 }\end{array}$} & None & 49 & $24 / 76$ & $>99$ & $>99$ \\
\hline & Glycerol & 31 & $19 / 81$ & 84 & $>99$ \\
\hline & L-Glutamate & 48 & $18 / 88$ & 88 & $>99$ \\
\hline
\end{tabular}

--:- Not detected.

Table 6. The reduction of $\alpha$-keto esters and aromatic $\alpha$-keto amide by $G$. hydrophobica NBRC16057.

\begin{tabular}{|c|c|c|c|c|c|c|c|c|c|}
\hline \multirow[b]{2}{*}{ Product } & \multicolumn{3}{|c|}{ No Additive } & \multicolumn{3}{|c|}{ Glycerol } & \multicolumn{3}{|c|}{ L-Glutamate } \\
\hline & $\begin{array}{c}\text { Conv. } \\
(\%)\end{array}$ & $\begin{array}{l}\text { e.e. } \\
(\%)\end{array}$ & $R / S$ & $\begin{array}{c}\text { Conv. } \\
(\%)\end{array}$ & $\begin{array}{l}\text { e.e. } \\
\text { (\%) }\end{array}$ & $R / S$ & $\begin{array}{c}\text { Conv. } \\
(\%)\end{array}$ & $\begin{array}{l}\text { e.e. } \\
\text { (\%) }\end{array}$ & $R / S$ \\
\hline $2 a$ & 41 & 40 & $S$ & 30 & 41 & $S$ & $>99$ & 46 & $S$ \\
\hline $2 b$ & 96 & 15 & $S$ & 78 & 22 & $S$ & 80 & 54 & $S$ \\
\hline $2 c$ & $>99$ & 18 & $S$ & 89 & 15 & $S$ & $>99$ & 86 & $S$ \\
\hline $2 d$ & 82 & 54 & $S$ & 77 & 38 & $S$ & $>99$ & $>99$ & $S$ \\
\hline $2 e$ & 65 & 28 & $S$ & 38 & 17 & $S$ & 92 & $>99$ & $S$ \\
\hline $2 \mathrm{f}$ & 59 & 35 & $R$ & 44 & 24 & $R$ & 60 & 44 & $R$ \\
\hline $2 \mathrm{~g}$ & 84 & 56 & $S$ & 78 & 88 & $S$ & $>99$ & 45 & $R$ \\
\hline $2 \mathrm{~h}$ & 91 & $>99$ & $R$ & 30 & $>99$ & $R$ & 54 & 36 & $S$ \\
\hline $2 \mathrm{i}$ & 16 & 25 & $R$ & 10 & 20 & $R$ & 3 & 21 & $R$ \\
\hline
\end{tabular}

Table 7. The reduction of $\alpha$-keto esters and aromatic $\alpha$-keto amide by G. hydrophobica NBRC108250.

\begin{tabular}{|c|c|c|c|c|c|c|c|c|c|}
\hline \multirow[b]{2}{*}{ Product } & \multicolumn{3}{|c|}{ No Additive } & \multicolumn{3}{|c|}{ Glycerol } & \multicolumn{3}{|c|}{ L-Glutamate } \\
\hline & $\begin{array}{c}\text { Conv. } \\
(\%)\end{array}$ & $\begin{array}{l}\text { e.e. } \\
(\%)\end{array}$ & $R / S$ & $\begin{array}{c}\text { Conv. } \\
(\%)\end{array}$ & $\begin{array}{l}\text { e.e. } \\
(\%)\end{array}$ & $R / S$ & $\begin{array}{c}\text { Conv. } \\
(\%)\end{array}$ & $\begin{array}{l}\text { e.e. } \\
\text { (\%) }\end{array}$ & $R / S$ \\
\hline $2 a$ & 38 & 24 & $S$ & 27 & 36 & $S$ & $>99$ & $>99$ & $S$ \\
\hline $2 b$ & 23 & 19 & $S$ & 51 & 10 & $S$ & 75 & 78 & $S$ \\
\hline $2 c$ & 3 & 30 & $S$ & 10 & 55 & $S$ & 91 & 89 & $S$ \\
\hline $2 d$ & 18 & 45 & $S$ & 23 & 63 & $S$ & 88 & 82 & $S$ \\
\hline $2 e$ & 55 & 32 & $R$ & 32 & 21 & $R$ & 83 & 79 & $R$ \\
\hline $2 f$ & 28 & 65 & $R$ & 36 & 45 & $R$ & 70 & 81 & $R$ \\
\hline $2 g$ & 44 & 20 & $S$ & 29 & 38 & $S$ & 90 & 45 & $S$ \\
\hline $2 \mathrm{~h}$ & 69 & 72 & $S$ & 40 & 81 & $S$ & 77 & 36 & $S$ \\
\hline $2 \mathrm{i}$ & 7 & 66 & $R$ & 12 & 79 & $R$ & 54 & 80 & $R$ \\
\hline
\end{tabular}


(S)-hydroxy esters ( $>99 \%$ e.e.) stereospecifically.

As shown in Table 8, in the reduction of $\beta$-keto ester ( $1 \mathrm{j}$ ) by G. malaquae NBRC108250 wet cells, the conversion rate and syn/anti ratio of the produced $\beta$-hydroxy ester ( $2 \mathbf{j}$ ) were low and were not improved by the introduction of additives. In contrast, the reduction of $1 \mathfrak{j}$ by the wet cells of the NBRC16057 strain stereospecifically produced the corresponding alcohol syn- $(2 R, 3 S)-2 \mathbf{j}$ in high conversion rate (81\%). Furthermore, when L-glutamate was introduced as an additive to the reduction of $\mathbf{1 j}$, the stereoselectivity (syn/anti ratio and e.e.) of the product remained high and the conversion rate was improved to $98 \%$. More specifically, in this reaction, the substrate was reduced to only one of the four theoretically possible stereoisomers. We reported in a previous paper that reduction by the wet cells of Dactylosporangium sp. NBRC101730 strain specifically reduces $1 \mathrm{j}$ to the corresponding $\beta$-hydroxy ester having anti- $(2 S, 3 S)$ form [15]. In other words, we succeeded in the specific preparation of syn- $(2 R, 3 S)$ and an$t i-(2 S, 3 S)$ forms of $2 \mathrm{j}$ by using two strains from different actinomycete genera, G. hydrophobica NBRC16057 strain and Dactylosporangium sp. NBRC101730 strain as shown in Figure 2.

In this study, the introduction of glycerol could not improve the conversion rate of the reduction, while the addition of L-glutamate improved the conversion rates. These results are likely due to the fact that the enzyme (keto ester reductase) involved in the reduction of the substrate depends on NADPH, and the coenzyme is excessively supplied during oxidative degradation of the added L-glutamate. In future work, we aim to purify and characterize the reductase from actinomycete whole cells and elucidate the reaction mechanism at the enzyme molecular level.

Table 8. The reduction of ethyl 2-methylacetoacetate by two Gordonia strains.

\begin{tabular}{cccccc}
\hline \multirow{2}{*}{$\begin{array}{c}\text { Strain/NBRC No. } \\
\end{array}$} & Additive & Conv. (\%) & Syn/Anti & \multicolumn{2}{c}{ e.e. (\%) } \\
\cline { 5 - 5 } G. hydrophobica & None & 81 & $>99 /<1$ & $>99$ & --- \\
NBRC16057 & Glycerol & 59 & $90 / 10$ & $>99$ & $>99$ \\
& L-Glutamate & 98 & $>99 /<1$ & $>99$ & --- \\
G. malaquae & None & 33 & $68 / 32$ & 28 & $>99$ \\
NBRC108250 & Glycerol & 18 & $55 / 45$ & 44 & $>99$ \\
& L-Glutamate & 52 & $72 / 28$ & 39 & $>99$
\end{tabular}

---: Not detected.

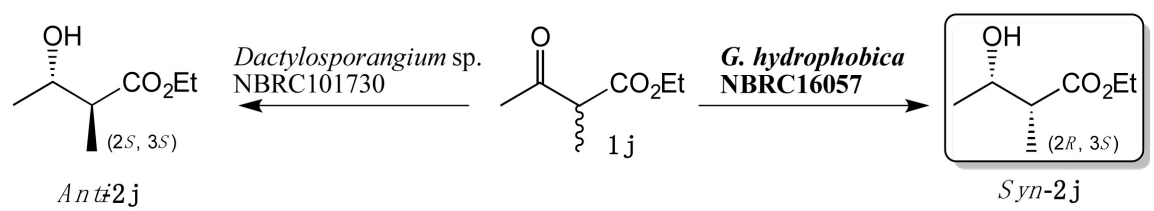

Figure 2. The stereospecific reduction of ethyl 2-methylacetoacetate by two actinomycetes. Left direction: Reference 15, Right direction: in this study. 


\section{Conclusion}

We discovered reducing activities for nine keto esters and an aromatic $\alpha$-keto amide in Agromyces strains from the Microbacteriaceae family and Gordonia strains from the Gordoniaceae family. We also found that the introduction of L-glutamate as an additive improved the conversion rate and stereoselectivity of the product in the reduction of some substrates. Furthermore, we have demonstrated that the G. hydrophobic NBRC16057 strain cultured in the 230 medium is an excellent and useful biocatalyst for the stereoselective reduction of ethyl 2 -methylacetoacetate to the corresponding alcohol with $s y n-(2 R, 3 S)$ form.

\section{Conflicts of Interest}

The authors declare no conflicts of interest.

\section{References}

[1] Faber, K. (2003) Biotransformations in Organic Chemistry. A Textbook. 5th Edition, Springer, Berlin.

[2] Roberts, S.M., Turner, N.J., Willetts, A.J. and Turner, M.K. (1995) Introduction to Biocatalysis Using Enzymes and Micro-Organisms. Cambridge University Press, New York. https://doi.org/10.1017/CBO9780511752254

[3] Ishihara, K., Hamada, H., Hirata, T. and Nakajima, N. (2003) Biotransformation Using Plant Cultured Cells. Journal of Molecular Catalysis, B: Enzymatic, 23, 145-170. https://doi.org/10.1016/S1381-1177(03)00080-8

[4] Nakamura, K., Inoue, K., Ushio, K., Oka, S. and Ohno, A. (1988) Stereochemical Control on Yeast Reduction of Keto Esters. Reduction by Immobilized Bakers' Yeast in Hexane. Journal of Organic Chemistry, 53, 2589-2593. https://doi.org/10.1021/jo00246a035

[5] Nakamura, K., Miyai, T., Nagar, A., Oka, S. and Ohno, A. (1989) Stereochemical Control in Microbial Reduction. 9. Diastereoselective Reduction of 2-Alkyl-3Oxobutanoate with Bakers' Yeast. Bulletin of the Chemical Society of Japan, 62, 1179-1187. https://doi.org/10.1246/bcsj.62.1179

[6] Nakamura, K., Kawai, Y., Kitayama, T., Miyai, T., Ogawa, M., Mikata, Y., Higaki, M. and Ohno, A. (1989) Asymmetric Reduction of Ketones with Microbes. Bulletin of the Institute for Chemical Research, Kyoto University, 67, 157-168. http://hdl.handle.net/2433/77299

[7] Kawai, Y., Takanobe, K. and Ohno, A. (1995) Stereochemical Control in Microbial Reduction. XXV. Additives Controlling Diastereoselectivity in a Microbial Reduction of Ethyl 2-Methyl-3-Oxobutanoate. Bulletin of the Chemical Society of Japan, 68, 285-288. https://doi.org/10.1246/bcsj.68.285

[8] Ishihara, K., Nishitani, M., Yamaguchi, H., Nakajima, N. and Nakamura, K. (1997) Preparation of Optically Active-Hydroxy Esters: Stereoselective Reduction of $\alpha$-Keto Esters Using Thermophilic Actinomycetes. Journal of Fermentation and Bioengineering, 84, 268-270. https://doi.org/10.1016/S0922-338X(97)82068-5

[9] Ishihara, K., Yamaguchi, H., Hamada, H., Nakajima, N. and Nakamura, K. (2000) Stereocontrolled Reduction of $\alpha$-Keto Esters with Thermophilic Actinomycete, Streptomyces thermocyaneoviolaceus IFO14271. Journal of Molecular Catalysis, B: Enzymatic, 10, 429-434. https://doi.org/10.1016/S1381-1177(99)00115-0 
[10] Ishihara, K., Nishimura, M., Nakashima, K., Machii, N., Miyake, F., Nishi, M., Yoshida, M., Masuoka, N. and Nakajima, N. (2010) Preparation of Chiral 2-Chloromandelamide: Stereoselective Reduction of an Aromatic $\alpha$-Keto Amide with Actinomycete. Biochemistry Insights, 3, 19-24. https://doi.org/10.4137/BCI.S4231

[11] Ishihara, K., Fujita, A., Sakiyama, A., Kobayashi, Y., Hori, K., Maruike, K., Masuoka, N., Nakajima, N. and Hamada, H. (2013) Preparation of Chiral Hydroxy Esters Using Actinobacteria: Biocatalyst Activity of Marine-Derived Micromonospora and Streptomyces Strains. Open Journal of Applied Sciences, 3, 116-122. https://doi.org/10.4236/ojapps.2013.31017

[12] Ishihara, K., Kondo, A., Kashima, H., Yoshimura, T., Hori, G., Hamada, H. and Masuoka, N. (2015) Biocatalytic Preparation of Chiral Alcohols: Stereoselective Reduction of Carbonyl Compounds Using Two Strains of the Streptomycetaceae Family-Streptacidiphilus and Kitasatospora. International Journal of Current Microbiology and Applied Sciences, 10, 300-309. https://www.ijcmas.com/vol-4-10/K.\%20Ishihara,\%20et\%20al.pdf

[13] Ishihara, K., Chiba, A., Ohnishi, K., Ohkawa, A., Mizote, Y., Uesugi, D., Masuoka, N., Nakajima, N. and Hamada, H. (2017) Microbial Preparation of Chiral Alcohols: Stereoselective Reduction of Carbonyl Compounds using Two Genera of the Streptosporangiaceae Family-Streptosporangium and Nonomuraea. International Journal of Current Microbiology and Applied Sciences, 6, 707-717. https://doi.org/10.20546/ijcmas.2017.608.090

[14] Ishihara, K., Nagai, H., Takahashi, K., Nishiyama, M. and Nakajima, N. (2011) Stereoselective Reduction of $\alpha$-Keto Ester and $\alpha$-Keto Amide with Marine Actinomycetes, Salinispora Strains, as Novel Biocatalysts. Biochemistry Insights, 4, 29-33. https://doi.org/10.4137/BCI.S7877

[15] Ishihara, K., Morita, K., Nishimori, Y., Okamoto, S., Hiramatsu, Ohkawa, A., Uesugi, D., Yanagi, M., Hamada, H., Masuoka, N. and Nakajima, N. (2019) Biocatalytic Reduction of Carbonyl Compounds by Actinobacteria from Two Genera of the Micromonosporaceae Family: Actinoplanes and Dactylosporangium. International Journal of Current Microbiology and Applied Sciences, 8, 920-931. https://doi.org/10.20546/ijcmas.2019.804.106

[16] Ishihara, K., Yamaguchi, H., Hamada, H., Nakamura, K. and Nakajima, N. (2000) Asymmetric Reduction of $\alpha$-Keto Esters with Thermophilic Actinomycete: Purification and Characterization of $\alpha$-Keto Ester Reductase from Streptomyces thermocyaneoviolaceus IFO14271. Journal of Molecular Catalysis, B: Enzymatic, 10, 419-428. https://doi.org/10.1016/S1381-1177(99)00114-9

[17] Ishihara, K., Yamaguchi, H., Omori, T., Uemura, T., Nakajima, N. and Esaki, N. (2004) A Novel Zinc-Containing $\alpha$-Keto Ester Reductase from Actinomycete: An Approach Based on Protein Chemistry and Bioinformatics. Bioscience, Biotechnology, and Biochemistry, 68, 2120-2127. https://doi.org/10.1271/bbb.68.2120

[18] Ishihara, K., Kato, C., Yamaguchi, H., Yoshida, M., Ikeda, N., Hamada, H., Masuoka, N. and Nakajima, N. (2008) Stereoselective Reduction of Carbonyl Compounds with Actinomycete: Purification and Characterization of Three $\alpha$-Keto Ester Reductases from Streptomyces avermitilis. Bioscience, Biotechnology, and Biochemistry, 72, 3249-3257. https://doi.org/10.1271/bbb.80537

[19] Mitsuhashi, K. and Yamamoto, H. (2005) Method for Producing Optically Active Mandelic Acid Derivative. Japan Kokai Tokkyo Koho, 2005-295817. 